\title{
Incidence of fistula subsequent to anal abscesses
}

\author{
*Dr.Jabbar Ali Hussien \\ ${ }^{* *}$ Dr. Majid Hamid Hussien \\ Almadain General Hospital / Ministry of Health / Iraq \\ E-mail / alimsaleam@gmail.com \\ Mobile / 009647725503941
}

\section{Abstract}

A prospective study about the incidence of fistula subsequent to perianal abscesses, the study included 216 patients admitted to AL-kindy general hospital from 2018 to 2020, all of them male persons.

All the abscesses were managed by incision \& drainage only 11 without prodding or exploration of anorectal area.

The patients studied were classified into 3 groups to the incidence of occurrence of perianal abscesses: Croup 1 : patient with no pervious episode of anorectal sepsis, in those the incidence of fistula was $30.5 \%$ Group II : Patient with only one previous episode of anorectal sepsis, in those the incidence of fistula was $72.2 \%$.

Group III : Patients who did not get proper surgical treatment \& the abscess opened spontaneously \& all of them had simple perianal abscess, in those the incidence of fistula was $100 \%$.

The study showed there is no need for rectal exploration in each \& every case of anorectal sepsis at first encounter because only $30.5 \%$ of those patient will develop fistula , In addition to the risk to operate on such inflamed area \& the anorectal exploration should be kept for patient seen for the second or third time with recurrence of anorectal or persistent anorectal fistula following incision \& drainage. 


\section{Introduction}

Perianal abscesses are common surgical emergency in all hospitals where there is casualty department.(1) Understanding the anatomy of pelvic floor and anorectal region is very important to appreciate the origin and ramification of the fistula, Reduced to its simplest from Anorectal region consist of two structure the inner structure is the lower end of the circular muscle of rectum which become thick and round and called the internal sphincter.

Surrounding this, there is a funnel of pelvic floor muscles formed by the levator ani. puborectalis and external sphincter muscle.

Around the ano rectum there are several potential spaces that are normally filled with areolar tissue or fat. (2)

These spaces are :

1. Perianal space

2. Ischio rectal space

3. Inter sphinctetric space

4. Pelvi rectal space

These spaces may be infected and abscess can be formed with sub sequent fistula formation. The infection usually started in anal glands which are 8-12 in number their basal found in potential space

(( the inter sphinctric plan $))$ between the internal sphincter and the external sphincter.

Anorectal abscess usually classified by site of the origin, but as the infection process spread other space become involved making clear division impossible. (3)

$\begin{array}{lc}\text { Perianal abscess } & 60 \% \\ 2 \text {-Ischio rectal } & 30 \% \\ \text { Inter sphincter } & 6 \% \\ \text { High sphincteric } & 3 \% \\ \text { Pelvi rectal } & 1 \%\end{array}$

Fig. (1) pathways of infection in perianal spaces

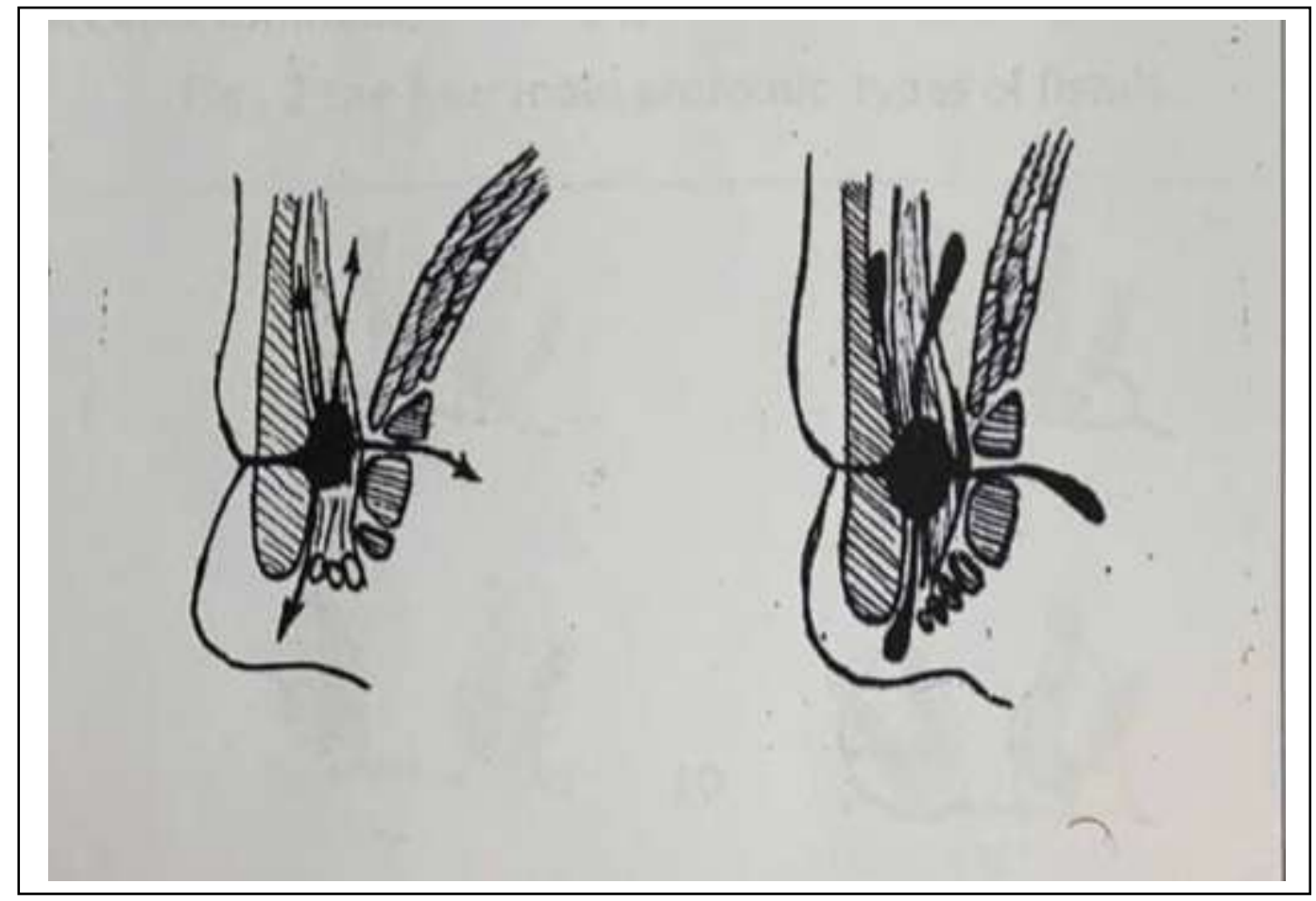


Fistula in ano is an inflammatory track with secondary open ing ( external $))$ in parietal skin and primary opening (( 9 inter 5- nal $))$ in anal canal at the dentate line and this track kept 3 . opened by infecting source which is anal gland most ano Rectal fistula are complication of abscess originate in these glands

Eisenhammer use the term fistulas abscess to stresses this Relationship between the abscesses and fistula formation.

Most precise classification of fistula in ano has been pro posed by parks : (6)

Fistula classified in 4 categories based on the relationship of sphincter muscle.

1. Inter sphinctric $\quad 70 \%$

2. Trans sphinctric $\quad 25 \%$

3.Supra sphinctric $\quad 4 \%$

4. Extra sphinctric $\quad 1 \%$

Fig. 2 the four main anotomic types of fistula.

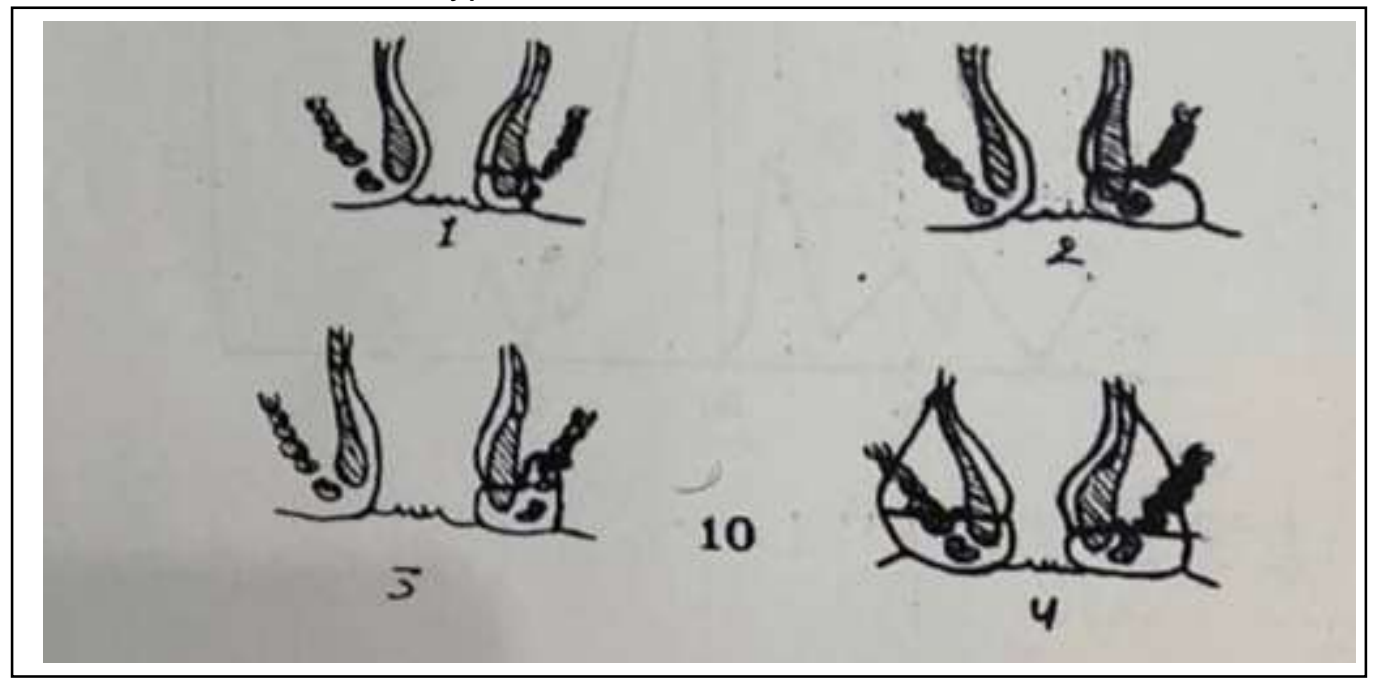

\section{Patients \& methods}

The study included 216 patients admitted to AL-kindy general Hospital.

The mean ages of patients was 28 years all of them were male, with median duration of symptoms before presentation was 5 days.

Fig.2 Incidence of perianal abscess related to the age.

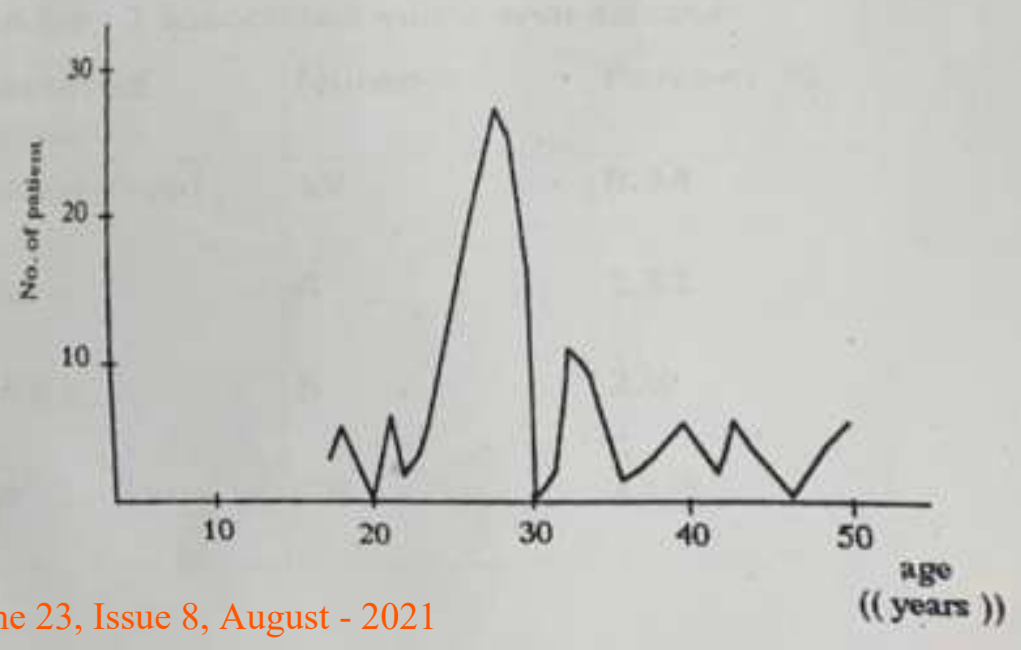


$60 \%$ of patient receive antibiotic irregularly before referred to hospital. 194 of patient had no previous episode of perianal abscess. 54 of patient had suffered from previous one episode of anorectal sepsis. 13 patients their abscess opened spontaneously because of delayed treatment. Only 29 patient had associated with minor anal disease : Hemorrhoid in 19 patient, fissure in ano in 4 patient.

6 patient give strong history of intractable pruritus in ano (table NO.1) Table No. 1 associated minor anal disease

\begin{tabular}{|l|l|l|}
\hline $\begin{array}{l}\text { Associated } \\
\text { Disease }\end{array}$ & Number & Percent \% \\
\hline Haemorrhoid & 19 & 8.84 \\
Fissure & 4 & 1.81 \\
pruritus & 6 & 2.8 \\
Total & 29 & 13.4 \\
\hline
\end{tabular}

Any patient with existing condition predispose to sepsis was excluded crohn's disease TB or Hodgkin lymphoma. 137patient who represent all patient with perianal type of abscess drained under local anesthesia, while the other type abscess drained under general anesthesia , probing and exploration the abscess cavity were done, patient instructed to take 2 sit of hot baths At first post operative visit which usually after 15 days, all patient, underwent proctoscopic examination to find the internal opening of fistula if it formed. Patient then followed up every 2 month for 6 months and every 6 months for the rest of the time. Patient who develop fistula were advised to be treated accordingly. 


\section{Result}

216 patients were included in this study all of them were male.

The type of anorectal abscesses were evaluated ( Table NO. 2 ) simple parianal abscesses was found in 137 patient ( $63.4 \%)$ ischiorectal abscesses was found in 137 patient $(28.2 \%$ ) and 18 patient $(8.3 \%)$ were found to have inter sphinctric abscesses.

Table No. 2 type of abscesses

\begin{tabular}{|l|l|l|}
\hline Type & Number & Percent \% \\
\hline Perianal & 137 & 63.48 \\
Ischiorectal & 61 & 28.2 \\
intersphinctric & 18 & 8.3 \\
Total & 216 & 100 \\
\hline
\end{tabular}

Percent \% 63.48

For purpose of analysis the incidence of fistula subsequent to anal abscesses, we classified the patient in this study in 3 groups:

Croup 1: patient with no history of previous episode

of anorectal sepsis \& this incidence 149

patient( $689 \%$ ) patient.

Group II : Patient with previous one attack of

Perianal abscess and this include 54

patient $(25 \%)$.

Group III: Patients abscess who did not take proper

Surgical treatment \& the abscess opened

patient $(6 \%)$ sponteously and this group include 13

the incidence of fistula was comparable in those 3 groups and the study show that $(30.8$ $\%)$ of the patient in first group will develop fistula while was $(72.2 \%)$ in patient of second group and $(100 \%)$ in third group (Table No. 3)

Table No. 3 Incidence of fistula

\begin{tabular}{|c|l|l|l|}
\hline Group No & $\begin{array}{l}\text { Number of } \\
\text { Patient }\end{array}$ & $\begin{array}{l}\text { Patient with } \\
\text { fistula }\end{array}$ & Percent \% \\
\hline Group I & 149 & 46 & 30.8 \\
Group II & 54 & 39 & 72.2 \\
Group III & 13 & 13 & 100 \\
\hline
\end{tabular}




\section{Discussion}

Fistula in ano and perianal abscesses are common surgical problem, they are more common in male and high incidence be- in third and fourth decade. (1) Most anorectal fistula are complication of anorectal abscess. Mazier reported in his study about anorectal fistula their was history of previous anorectal abscess in about $(68 \%)$ of his patient (2) Some and his colleagues have reported that $2 / 3$ of patient under go incision and drainage of abscesses will have fistula and in other study done by the same surgeon, he did his study on (232) patients with fallow up for 13 years he show that (34\%) of the patient in his study did not develop fistula . (3) In extensive study done in 3 hospitals in united kingdom done by M .C.W, inset the study showed that $(32 \%)$ of patient who have abscess and treated by incision and drainage will develop fistula and this result is similar to our result in this study. (7)

In other study did by Hughes he state that $(75 \%)$ of patients who had anal abscess and drainage had further problem, but he did not specify the incidence of fistula. (3) From the result of this study which appear that $(30.5 \%)$ only will develop fistula and fertilization is not inevitable, we prefer the conservative management is incision and drainage and if fistula dose develop spontaneously and the associated ano rectal disease can be more safely and successfully treated at the time fistulatomy

\section{References}

1- Forrest A.P.M : patient \&practice of surgery church livingstone .dr.1983,456.

2- Stanly M. Goldberg : Schwart, principle of Surgerymcgraw - hill 5 th ed.1988.1294.

3 - Scom A.Joseph : incidence of fistulas subsequent of anal abscesses. dis . Colon Rectum , 196, 17:357.

4 - A.J. Harding \& chaeles V.Mann :Bailey \& love short practice of surgery .Lewis 20

th ed.1988 p. 1194

5- Ira J .Kodner : Colon, rectal 7 anal syrgery. mosby. 1985 ed. p.91 1985.

6 - Parks, A.G., Gordon

,P.H., and Hardcastie ,J.D. A classification of fistula - in -ano. Br. J. Surg., 1976, 63:1

7- Winslett M.C, Allam, A.: Ano rectal sepsis as presen tation of occult Rectal \& system Disease Dis . Col. \& rectum 1988.597 - 601.

8- Held, Douglus : management of ano rectal Horseshoe abscess \& fistula : Dis col. rectum Dectum 1986 . 793 - 7. 9- Adams D. : fistula in ano : Surgery - Gyn and obst No -vember 1981. 153.731 -2. 